\title{
How to Improve Complex and Creative Knowledge Work in 21st Century Organizations with Kanban
}

\author{
Gabe Abella \\ Florida, USA
}

\author{
Shannon Arvizu \\ California, USA
}

\begin{abstract}
How can teams better produce complex and creative knowledge work in today's competitive and fast-moving business environment? How can team coaches and organizational design practitioners equip teams to consistently produce high value for their stakeholders, given the social and technical factors associated with sophisticated knowledge work production? As researchers and team performance coaches, we see an urgent need to offer interventions that account for the demand placed on teams, the cognitive load and capacity of teams, and the emergent and unpredictable nature of knowledge work. In this position paper, we build upon existing team performance research by introducing the Kanban Method to improve the system of work. We outline the Agendas, Principles, and Practices of Kanban, as well as share resources for practitioners to learn more, so that we can all help teams reliably and consistently accomplish goals in today's business environment.
\end{abstract}

Keywords: team coaching, Kanban Method, socio-technical systems, organizational design

\section{Introduction}

How can teams better produce complex and creative knowledge work in today's competitive and fast-moving business environment? How can team coaches and organizational design practitioners equip leaders and teams to consistently produce high value for their stakeholders, given the social and technical factors associated with sophisticated knowledge work production? These questions are not inconsequential.

Organizations are struggling to sustain performance, as evidenced by the shortened tenure of companies in the S\&P 500 in recent years. Knowledge workers are under significant pressure to create value in conditions that $80 \%$ of companies describe as "complex" or "highly complex" (Deloitte 2014; 2015). 
To generate value in these conditions, employees are working longer hours ( $86 \%$ of males and $67 \%$ of females in America work more than 40 hours) (Wesley, 2019) and taking fewer vacations (Americans left 662 million unused vacation days last year, forfeiting $\$ 66$ billion in benefits) (Project: Time Off, 2017).

To add to the complexity, employees experience a significant cognitive load on a daily basis, where the average U.S. worker spends $25 \%$ of their day reading or answering emails, on top of their daily tasks and meetings (Deloitte $2014 ; 2015)$. It may come as no surprise, then, to note that productivity gains have slowed to a crawl since 2011 (U.S. Bureau of Labor Statistics, 2018) and that engagement levels of U.S. workers, while improving, are only at $34 \%$ (Harter, 2018).

Given this current predicament, how can team coaches and organizational design practitioners help? Decades of research have pinpointed particular focus areas for improving the team capabilities of knowledge workers. Through the pioneering team performance research of J. Richard Hackman, Ruth Wageman, and Peter Hawkins, coaches have at their disposal useful models such as 'Six Conditions of Team Effectiveness' (Hackman, 2002; Wageman et al., 2012) and 'Five Disciplines of Systemic Team Coaching' (Hawkins, 2017) for assessing and intervening to improve performance at the team level of an organization.

These models focus on the creation of necessary conditions for effective performance. For example, drawing on the Hackman and Wageman model (2002), there are three essential conditions (real team, compelling direction, and right people) and three enabling conditions (sound structure, organizational support, and team coaching) that account for the majority of a team's effectiveness. Drawing on the Hawkins model (2017), there are five disciplines for the creation of high performing teams. It includes two that are internal to the team (the clarifying discipline of clear goals and roles and the co-creating discipline of team norms and dynamics), two that are external to the team (the commissioning discipline of contracting with stakeholders and the connecting discipline of engagement with stakeholders), and one that encompasses internal and external tasks and process (the core learning discipline for ongoing reflection and learning).

Both models are highly effective for designing an optimal social system of a team. They emphasize the importance of agreed-upon norms, healthy working relationships, and the need to establish a clear and compelling 
direction based on the needs of the team's stakeholders, as well as maintain ongoing relationships with those stakeholders.

That said, there is a need to improve how we think about the work system of a team and how it interacts with its environment while performing complex and creative knowledge work. While there is a nod to task design within these models, this is probably the least articulated element of existing team performance models. Moreover, existing interventions for improving task design are focused on clarity of goals and tasks, and not on the design of actual work. Furthermore, the existence of practices and interventions that help teams manage and improve the system of work are scarce to non-existent amongst present popular team coaching capabilities and toolkits. There is an implicit assumption that, when it comes to task design and execution, teams use their own best judgment on how to organize their work.

It's been our experience, as researchers and team performance coaches who regularly work with highly talented, creative, and innovative teams in Silicon Valley, as well as in the rest of the U.S. and internationally, that there is an urgent need to offer interventions to help teams structure their complex work in environments of uncertainty.

In particular, we need an updated team performance model that accounts for:

- the demand placed on teams

- the cognitive load and capacity of teams

- the emergent and unpredictable nature of knowledge work

In this position paper, we build upon existing team performance research to incorporate principles and practices that help teams more reliably and consistently accomplish goals in today's complex business environment.

To date, the models that are available to us have yet to fully conceptualize the system of work within teams and organizations. The system of work includes demand (how work enters the team), capabilities (the abilities of the team to service that demand), workflows (how value is created through the team), and policies (agreed upon norms for managing demand, capabilities and workflows). We argue that without understanding the system of work and designing effective interventions to improve this system of work, today's 
knowledge workers will find it difficult to produce high value for their stakeholders over time and will continue to be overworked and underutilized.

We also put forth that the primary aim of team coaches and organizational design practitioners should not only be to create the conditions for teams to produce high value for stakeholders, but to also cultivate collective intelligence, or the ability to collaboratively solve problems well across a wide variety of contexts. In today's business context, teams need to be able to surface issues, generate ideas, negotiate perspectives, make decisions, and perform tasks against an acceptable standard of measure under any circumstances that come its way.

To facilitate collective intelligence, coaches need a model that expands their focal point beyond social factors to also include system of work factors. To help in this manner, we draw from Social-Technical Systems theory and, in particular, from the Kanban Method.

In the pages that follow, we provide an overview of the Kanban Method, along with its core principles and agendas. We also speak to our experiences of implementing Kanban in a variety of work contexts, including established enterprises and technology startups. We conclude with a discussion of the strengths and limitations of the Kanban method and ways that team coaches and organizational designers might incorporate Kanban in their work with clients. We also point to resources throughout the paper for coaches to learn more and begin experimenting with these interventions to experience the benefits for themselves, their teams, and the organizations they serve.

\section{A Socio-Technical Systems Approach to Organizational and Team Coaching}

In order to help teams improve their system of work, coaches need an understanding of humane work design. For this, we draw from Socio-Technical Systems theory, which refers to the joint optimization of social and technical systems of an organization or team. As definitions, the social system refers to the values, norms, beliefs, relationships, emotions, memories, capacities, and psychological disposition of an organization or team. The technical system refers to the tools, techniques, artifacts, methods, procedures, and knowledge used by an organization or team to acquire inputs, transform inputs into outputs, and provide outputs or services to clients or customers (i.e. what we call in this paper the "system of work") (Passmore, 1988). Socio-Technical Systems theory is founded on two principles: (1) that the interaction of social and technical 
factors creates the conditions for successful performance and that (2) optimization of each aspect alone (social or technical) can lead to an increase in the quantity of unpredictable relationships that hinder the system's performance.

Socio-Technical Systems theory emerged from the classic study of British coal mines in the late 1940s (Trist \& Bamforth, 1951). In this study, management researchers explicitly identified the interdependence of the social and technical systems. They found that changes to the technical part of the coal mining system (i.e. increased division of labor) led to negative social consequences (increased absenteeism, conflicts, and accidents), resulting in lower productivity and negative economic consequences. When miners developed cooperative ways of working between task groups, based on intimate knowledge of their own work, accidents declined and productivity increased.

The seminal study established the idea that there were better ways to organize work than those that followed a technical rationality alone (i.e. TaylorFordism). It also put forth the notion that self-regulating workgroups should inform the design and implementation of the joint optimization in order to create the conditions for superior economic performance and a better work environment. Researchers followed suit with an extensive set of studies in a variety of work environments across several countries in the $1950 \mathrm{~s}, 60 \mathrm{~s}$, and 70 s and the insights from these studies make up the foundation of the sociotechnical system (STS) field, which also includes a set of organizational design principles for collaborative work design (Shani et. al., 2007). The field has continued to evolve since, undergoing several waves of evolution (Mohr \& van Amelsvoort, 2016), and we propose that the Kanban Method is the current evolution of STS theory and practice.

As team coaches and organizational designers, our role is to help clients become aware of factors that disrupt the joint optimization of the social and technical aspects of their work and, ultimately, aid them in making choices that improve that joint optimization. Those choices include how the organization functions as a system, how change is introduced and managed, and how work systems are structured.

The Kanban Method provides a schema for thinking through those choices that honors the knowledge and capacity of those who are producing the work. Its greatest strength as a management method is that it makes work systems visible and provides a set of general principles that respects the abilities of teams to identify and solve business challenges. 


\title{
What Is the Kanban Method?
}

\author{
Kanban is a method for defining, managing, and improving services that \\ deliver knowledge work, such as professional services, creative \\ endeavors, and the design of both physical and software products. It may \\ be characterized as a "start from what you do now" method - a catalyst \\ for rapid and focused change within organizations. (Anderson \& \\ Carmichael, 2016)
}

The first kanban systems originated in the manufacturing sector in the early 1940s as a simple planning system to better manage work and inventory for Toyota automotive in Japan. Taiichi Ohno, an industrial engineer at the time, sought ways to increase the productivity and efficiency of Toyota so that it could better compete with its American automotive rivals. Ohno designed a system of work that achieved higher throughput with lower delivery times, in a way that empowered employees to develop and implement initiatives for continuous improvements.

Kanban systems were later applied to the Information Technology (IT) sector in 2004 by David J. Anderson, an engineering director who worked for Sprint, Motorola, and Corbis (a company privately owned by Bill Gates), before becoming the Chairman of Lean Kanban Inc. Building on the work of W. Edwards Deming, Eli Goldratt, Peter Drucker, Peter Senge, and Taiichi Ohno, Anderson further developed the Kanban Method to specifically improve the capabilities of organizations performing complex and creative knowledge work and enable them to survive and thrive in the Volatile, Uncertain, Complex, and Ambiguous (VUCA) realities of the $21^{\text {st }}$ century business climate (Anderson 2003; 2010; 2012; Anderson \& Zheglov 2017).

The Kanban Method, as articulated in its latest evolution by Anderson, is particularly instructive for helping organizations understand how it functions as a system, how change is introduced and managed, and how work systems are structured so that they can better deliver value for their stakeholders in an uncertain business environment. The Method is outlined in the Agendas, Principles, and Practices of Kanban, which are briefly introduced below. 


\section{Table 1. Core Components of the Kanban Method}

\begin{tabular}{|c|c|c|}
\hline $\begin{array}{l}\text { How does the } \\
\text { organization } \\
\text { function as a } \\
\text { system? }\end{array}$ & $\begin{array}{l}\text { The Three } \\
\text { Agendas of } \\
\text { Kanban }\end{array}$ & $\begin{array}{l}\text { - Survivability: Adapt and thrive under } \\
\text { uncertainty } \\
\text { - Service Orientation: Improve } \\
\text { predictability and lead time } \\
\text { - Sustainability: Balance demand and } \\
\text { capability }\end{array}$ \\
\hline $\begin{array}{l}\text { How is } \\
\text { change } \\
\text { introduced } \\
\text { and } \\
\text { managed? }\end{array}$ & $\begin{array}{l}\text { The Three } \\
\text { Change } \\
\text { Management } \\
\text { Principles }\end{array}$ & $\begin{array}{l}\text { - Start with what you do now } \\
\text { - Gain agreement to pursue } \\
\text { improvement through evolutionary } \\
\text { change } \\
\text { - Encourage acts of leadership at all } \\
\text { levels }\end{array}$ \\
\hline $\begin{array}{l}\text { How to } \\
\text { design and } \\
\text { improve } \\
\text { work } \\
\text { systems? }\end{array}$ & $\begin{array}{l}\text { The Six } \\
\text { General } \\
\text { Practices }\end{array}$ & $\begin{array}{l}\text { 1. Visualize } \\
\text { 2. Limit Work-in-Progress (WIP) } \\
\text { 3. Manage Flow } \\
\text { 4. Make Policies Explicit } \\
\text { 5. Implement Feedback Loops } \\
\text { 6. Improve Collaboratively, Evolve } \\
\text { Experimentally }\end{array}$ \\
\hline
\end{tabular}

We describe these components in more detail in the following sections.

\section{The Three Agendas of Kanban}

To improve the system of work, coaches need to know where and how to intervene and invite change. Through the lens of the Kanban Method, the organization is composed of three systems: individuals and teams, teams of teams, and the whole organization (which includes the interactions between the organization, its customers, and the external environment) (Anderson \& Bozheva, 2018). The Three Agendas of Kanban specify the needs and potential interventions for each system (Burrows, 2014). 


\section{The Three Agendas of Kanban}

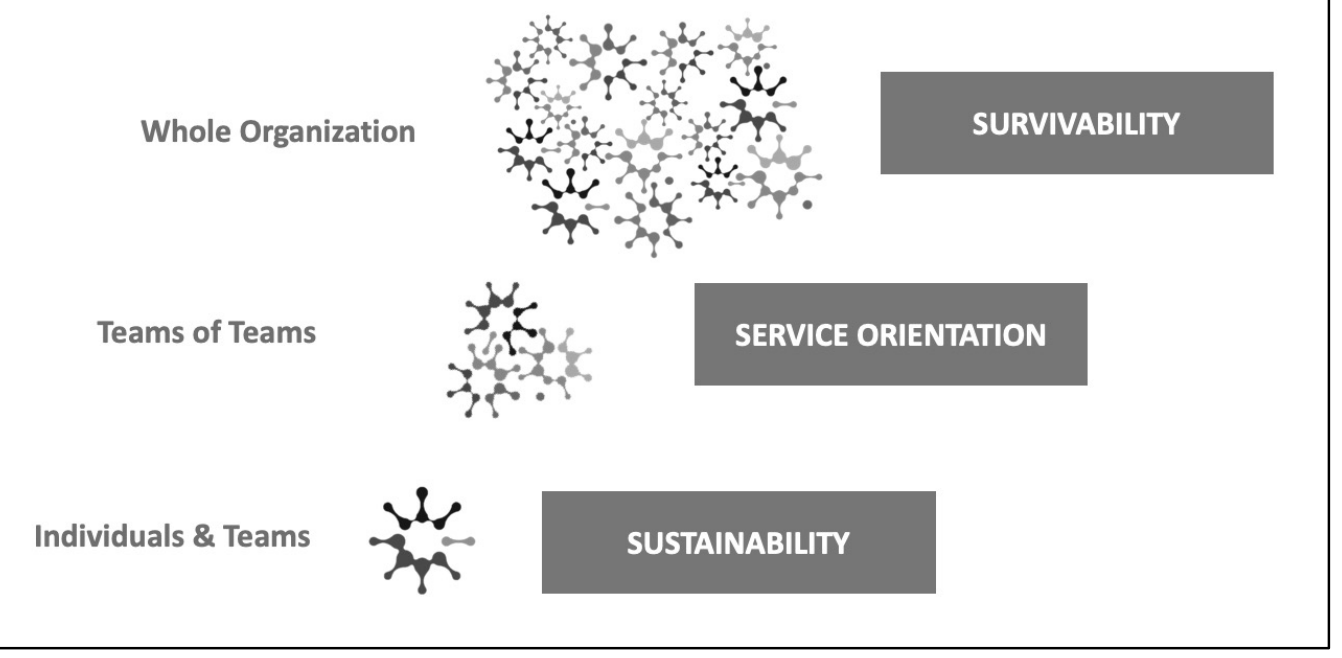

Figure 1. The system focus of the three agendas of Kanban

Survivability of the Whole Organization: Organizations need adaptive capabilities to survive and thrive in the presence of a rapidly changing external environment. The Survivability agenda helps organizations focus on building the capabilities that enable intelligent sensing of market changes by focusing on an organization's "fitness for purpose." This is done through the appropriate application of performance measures categorized as fitness criteria (i.e. key performance indicators (KPI) that matter most to customers), health indicators (i.e. vital signs that indicate an organization's ability to service customers), and improvement drivers (i.e. temporary metrics that have a secondary effect intended to influence a customer-facing KPI or health indicator). (Anderson \& Zheglov, 2017). With this information, organizations can ideally respond to changes faster than competitors and faster than the external world is changing (Anderson, 2016).

Service Orientation of Team of Teams: Teams often exist within an ecosystem of other teams, many of whom serve and depend on each other to fulfill the needs of customers. Seen in this way, teams have both external and internal customers. Kanban views the work performed for an internal or external customer as a sequence of services, instead of as functions or specializations in the organization. This is a departure from what is found in many companies today, where work is disaggregated into functional teams that can hinder a customer focus. Taking the Kanban Method approach means that 
the entire chain of services must be taken into consideration and managed as a whole in order to improve the flow of value to the end customers (Anderson \& Bozheva, 2018).

Sustainability of Individuals and Team: When it comes to knowledge work production, the creative and cognitive capacity of individuals and teams are an organization's greatest asset. Using a kanban system respects the human limits of knowledge workers and encourages organizations to consider the factors that lead to creating a sustainable environment where people and their good work can thrive and grow (Anderson, 2016).

\section{Introducing and Managing Change: The Three Change Management Principles of Kanban}

When introducing improvements to the system of work, coaches need to be mindful of the potential impacts to the social system of an organization or team. It's important to not introduce too much change at once, as well as to seek agreement on the change and to empower those who are affected by the change to be involved in the design and implementation of it.

In line with this philosophy, the Kanban Method has three change management principles. They include:

- Start with what you do now

- Gain agreement to pursue improvement through evolutionary change

- Encourage acts of leadership at all levels

Kanban's sensitivity to the impact of change on the individual and the social system of an organization, combined with its emphasis on incremental and evolutionary change, is what distinguishes it from deterministic managed change processes and programs promoted by typical management consulting firms.

The Kanban Method rejects all of these approaches on the basis that they typically introduce too much change all at once, and they suppose that the process designer is somehow smarter than the workforce and smart enough to understand all the complexities of the domain and the dynamics of the workflow. This approach of designing solutions or selecting them from a pattern catalog seems to have worked fairly well in deterministic domains and physical environments. The Kanban Method is based on the assumption that such an approach is problematic in complex, nondeterministic domains such as professional services, knowledge work and 
creative pursuits. In other words, 21 st Century businesses need a 21 st Century model for change management. This model should be based on evolutionary theory as it is compatible with and robust to the complexity, emergent and non-deterministic outcomes of modern work producing intangible goods. (Anderson, 2016)

These three change management principles also distinguish the Kanban Method from other approaches to improving the work of teams, such as Scrum or Holocracy. Scrum originated in 1986 by Hirotaka Takeuchi and Ikujiro Nonaka, management researchers, who were looking for a faster and more flexible approach to project management. Their research suggested looking at the project management process as a unit and not as an individual task. Their insights were later picked up by software project managers in the early 1990s, including Ken Schwaber and Jeff Sutherland, who were the first to consider how to use this approach to better deliver software on schedule and under budget. The approach consists of teams breaking up their work into timeboxed iterations, called sprints, and then tracking progress and re-planning in 15minute time-boxed stand-up meetings, called daily scrums.

Holocracy developed as a set of practices intended to establish more democratic forms of organizational governance. It originated within a company called Ternary Software. The company's founder, Brian Robertson, compiled and published the company's practices in 2007 under the term "holocracy" (Roberston, 2007). The core elements of the system include specific roles and structures for teams and meetings, as well as a governance process for updating roles and policies and an operational process for decision-making.

While the ultimate intention of both is to improve how work is produced, Scrum and Holocracy are largely deterministic frameworks that are processdriven. They promote changes to the technical system without recognizing the potential impacts on the social system. There is no specified approach for introducing change incrementally or seeking agreement among those who are affected by the change to implement the change. Furthermore, those who are affected by the change are not invited to shape the nature of the change. Rather, both approaches are fairly prescriptive in what is to be implemented, when, and by whom.

In our experiences in improving the system of work within teams, we have found that it's best to use an approach that minimizes abrupt radical change and involves the team in identifying problems and shaping processes. This is not to say Kanban does not account for the need for substantial change under certain circumstances. For organizations whose survival is threatened by 
external events or competitors, Kanban acknowledges that environmental forces can indeed provide the sufficient motivation for step change evolution of an organization (i.e. punctuated equilibria), but it should be clear that existential threats do not absolve leaders and Kanban practitioners from their responsibility to treat participants in the social system with dignity and respect.

\section{Designing Work Systems: The Six General Practices of Kanban}

To improve, coaches need to help teams visualize current processes to foster a deeper understanding of what's hindering consistent, high-quality knowledge work production. They also need to educate teams on potential interventions that could enhance their abilities to better meet the needs of stakeholders.

The Six General Practices of Kanban represent categories of specific practices that can be introduced to make tangible the invisible systems of knowledge work, as well as create the conditions for more effective and humane ways of working. The Kanban Maturity Model (Anderson \& Bozheva, 2018) introduces specific implementations of Kanban's six general practices which include:

- Visualize: Teams benefit from visualizing work on a kanban board by developing a shared understanding of objectives, work status, impediments, and risks.

- Limit Work-in-Progress: Teams benefit from establishing activity based work-in-progress limits by amplifying the impact of blocking issues and encourage their early and swift resolution.

- Manage Flow: Teams benefit from leveraging forecasting techniques by developing a quantitative understanding of the entire process to better manage capacity and customer expectations.

- Make Policies Explicit: Teams benefit from defining initial policies by establishing explicit criteria for making decisions related to work items and the process upon which the team will continually evolve.

- Implement Feedback Loops: Teams benefit from holding retrospectives by allowing the team to reflect on how they actually manage their work and how they can improve.

- Improve Collaboratively, Evolve Experimentally: Teams benefit from analyzing the impact and likelihood of blockers through the improvement of the team's risk management capabilities. 
Again, Kanban offers these practices not in a prescriptive manner, but more like a "menu" of options. We find this approach to be warmly accepted by the teams we coach because it empowers them with a new perspective through which to view their work and honors their own abilities to improve it. They also appreciate the specific and measurable ways of tracking improvements, through metrics such as lead time and flow efficiency.

Through these practices, teams experience a transformational shift in how they approach their work and begin to adopt the characteristics of selfmanaging teams. They surface and solve problems faster, with the help of tighter feedback loops with stakeholders, and collectively improve their abilities to learn over time through multiple delivery cycles. To learn more about how specific organizations and teams have implemented Kanban, see LeanKanban.com/case-studies.

\section{Incorporating Kanban into the Organizational Performance Toolkit}

To be of better service to today's organizations and teams, coaches would do well to pay attention to both the social system and the technical system, as well as the joint optimization of both.

Kanban provides a powerful way for coaches to improve the systems of work within teams and organizations. With its emphasis on the sustainability of teams, a service orientation to better meet the needs of internal and external customers, and a priority on survivability through building adaptive organizational capabilities, the Kanban Method is a flexible and relevant approach for today's organizational and team coaches. For more information on Kanban Method learning paths, see LeanKanban.com/project/tpath.

That said, Kanban is not a standalone method for improving a team's abilities to produce high-quality knowledge work. The Kanban Method, for example, does not speak to the design, launch, and ongoing coaching of teams. Given that team performance is an emergent property of a complex system, we believe strongly in integrating the Kanban Method's principles and practices with evidenced-based team coaching models such as Hackman \& Wageman's 'Six Conditions of Team Effectiveness' and Hawkins' 'Five Disciplines of Systemic Team Coaching.' We draw from these models to account for the social and structural needs of teams, based on their current evolution.

The Kanban Method also does not speak to the relational and developmental system of a team. We draw from positive psychology coaching, 
adult learning theory, experiential learning, and improvisation to lower learning anxiety and foster a growth mindset of teams. We introduce peer coaching techniques for use amongst the team, such as discovery questions, global listening, and feedforward, as well as business simulation activities (such as Okaloa Flowlab) to practice improving the work of a mock team before designing for and implementing changes to the work system. To learn more about Okaloa Flowlab business simulations visit Okaloa.com/flowlab.

Furthermore, because the Kanban Method is not prescriptive, teams also need the ability to develop a shared cognition around the problems to solve and the solutions to try. Most teams, in our experience, need additional skills in this domain. In addition to Kanban, we introduce facilitation practices to help teams diverge and converge on key issues.

It's also important to recognize that there are various levels of sophistication with Kanban, and different kinds of teams will have different needs. The kanban system of a software team building an Artificial Intelligence product with multiple dependencies will look different than the kanban system of a boutique marketing firm. The Systems Thinking Approach to Introducing Kanban (STATIK) is a collaborative approach for designing an initial kanban system that reflects the current state of the system of work and serves as the foundation for a team to improve through evolutionary change (Burrows, 2014). The Kanban Maturity Model further describes in detail many specific practices and provides guidance as to the appropriateness for introducing additional practices given an organization's current depth and breadth of Kanban adoption (Anderson \& Bozheva, 2018).

Lastly, we also recognize that certain limiting beliefs about the nature of work persist, even within organizations that are committed to improving the performance of knowledge workers and the environments within which they operate. We have found that, for example, there tends to be a persistent belief that teams have an obligation to continuously service infinite demand (even if that means working long hours, cancelling personal and professional trainings, and taking fewer vacations), without consideration of the finite capabilities of teams and the organization as a whole. We also find that there is a common belief that teams can "will" the conditions for timely completion, irrespective of what empirical data may show to be reasonably achievable. In more benign situations, this shows up as optimism bias. In other situations, it shows up as a form of coercion. The third most common bias we see is the belief that a team's perceived value is almost exclusively determined by the quantity of work they can complete (i.e. output of widgets/items), as opposed to achieving a 
meaningful outcome that furthers learning or mitigates early risk in environments of uncertainty. All of these limiting beliefs have the capacity to circumvent the benefits of a humane work design if not acknowledged and discussed by the coach and the team. The Kanban Method serves as a mirror to dispel these beliefs, as well as a provide a source of rich data, that can be used by teams to engage those with influence and authority within the organization to shift the mental models through which to view the system of work.

We're excited by the opportunity to improve the effectiveness of organizations and teams through the integration of models that consider both the social and technical systems of work. We live in a day and age where teams and organizations are under a great deal of pressure to create value and solve important complex problems in conditions of extreme uncertainty. As coaches and organizational designers, we need to continuously seek out alternatives and approaches that enable us to be of better service to our clients. The Kanban Method is one such approach that we are experiencing success with and are inspired by the promise of further integration and synthesis with existing team performance coaching models and tools.

\section{References}

Anderson, D. J. (2003). Agile management for software engineering: Applying the theory of constraints for business results. Upper Saddle River, NJ: Prentice Hall Professional Technical Reference.

Anderson, D. J. (2010). Kanban: Successful evolutionary change for your technology business, Sequim, WA: Blue Hole Press.

Anderson, D. J. (2012). Lessons in agile management: On the road to Kanban. Sequim, WA: Blue Hole Press.

Anderson, D. J. (2013, November 8). Kanban's 3 agendas [Blog post]. Retrieved from http://www.djaa.com/kanbans-3-agendas

Anderson, D. J. (2016, January 23). Kanban's change management principles [Blog post]. Retrieved from https://leankanban.com/kanbans-changemanagement-principles/

Anderson, D. J. (2016, January 24). Kanban's service delivery principles [Blog post]. Retrieved from https://leankanban.com/kanbans-service-deliveryprinciples/

Anderson, D. J. (2016, March 6). Survivability - Kanban's "Purple Cow" [Blog post]. Retrieved from https://anderson.leankanban.com/survivabilitykanbans-purple-cow/

Anderson, D. J., \& Bozheva, T. (2018). Kanban maturity model: Evolving fit for purpose organizations. Seattle, WA: Lean Kanban University Press. 
Anderson, D. J., \& Carmichael, A. (2016). Essential kanban condensed. Seattle, WA: Lean Kanban University Press.

Anderson, D. J., \& Zheglov, A. (2017). Fit for purpose: How modern businesses find, satisfy, \& keep customers. Seattle, WA: Blue Hole Press.

Burrows, M. (2014). Kanban from the inside. Sequim, WA: Blue Hole Press.

Deloitte. (2014). Global human capital trends 2014: Engaging the 21st-century workforce [PDF]. Retrieved from https://www2.deloitte.com/content/dam/Deloitte/ar/Documents/humancapital/arg_hc_global-human-capital-trends-2014_09062014\%20(1).pdf

Deloitte. (2015). Global human capital trends 2015: Leading in the new world of work [PDF]. Retrieved from

https://www2.deloitte.com/content/dam/Deloitte/na/Documents/humancapital/na_DUP_GlobalHumanCapitalTrends2015.pdf

Denning, S. (2018). The age of agile: How smart companies are transforming the way work gets done. New York, NY: American Management Association.

Liker, J. K., \& Convis, G. L. (2012). The Toyota way to lean leadership: Achieving and sustaining excellence through leadership development. New York, NY: McGraw Hill Education.

Drucker, P. F. (1999). Management challenges for the 21st century. New York, NY: Harper Collins e-books.

Edmundson, A. (1999). Psychological safety and learning behavior in work teams. Administrative Science Quarterly, 44(2), 350-383. doi:10.2307/2666999

Hackman, J. R. (2002). Leading teams: Setting the stage for great performances. Harvard, MA: Harvard Business Press.

Hackman, J. R. (2011). Collaborative intelligence: Using teams to solve hard problems. San Francisco, CA: Berrett-Koehler Publishers.

Hackman, J. R., \& Oldham, G. R. (1980). Work redesign. Reading, MA: Addison-Wesley Publishing Company.

Harter, J. (2018, August 26). Employee engagement on the rise in the US. Retrieved from https://news.gallup.com/poll/241649/employeeengagement-rise.aspx

Hawkins, P. (2017). Leadership team coaching: Developing collective transformational leadership. London, UK: Kogan Page.

Humble, J., Molesky, J., \& O’Reilly, B. (2015). Lean enterprise: How high performance organizations innovate at scale. Sebastopol, CA: O'Reilly Media. 
McChrystal, S., Collins, T., Silverman, D., \& Fussell, C. (2015). Team of teams: New rules of engagement for a complex world. New York, NY: Penguin Publishing Group.

Mohr, B. J., \& van Amelsvoort, P. (2016). Co-creating humane and innovative organizations: Evolutions in the practice of socio-technical system design. Portland, ME: Global STS-D Network Press.

Pasmore, W. A. (1988). Designing effective organizations: The sociotechnical systems perspective. New York: John Wiley \& Sons.

Pasmore, W. A., \& Sherwood, J. J. (1978). Sociotechnical systems: A sourcebook. San Diego, CA: University Associates.

Project: Time Off. (2017). The state of the American vacation 2017[PDF]. Retrieved from https://www.ustravel.org/sites/default/files/media_root/document/2017 May\%2023_Research_State\%20of\%20American\%20Vacation\%202017 .pdf

Reinertsen, D. G. (2009). The principles of product development flow: Second generation lean product development. Redondo Beach, CA: Celeritas Publishing.

Robertson, B. (2007, June 1). Organization at the leading edge: Introducing Holacracy ${ }^{\mathrm{TM}}$ evolving organization. Integral Leadership Review, 7(3). Retrieved from http://integralleadershipreview.com/5328-featurearticle-organization-at-the-leading-edge-introducing-holacracyevolving-organization/

Shani, A. B. (Rami), Mohrman, S. A., Pasmore, W. A., Bengt, S., \& A. Niclas (2007). Handbook of collaborative management research. Thousand Oaks, CA: Sage Publications, Inc.

Social relation. (n.d.). In Wikipedia. Retrieved January 31, 2019, from https://en.wikipedia.org/wiki/Social_relation

Takeuchi, H., \& Nonaka, I. (1986, January). The new new product development game. Harvard Business Review. Retrieved from https://hbr.org/1986/01/the-new-new-product-development-game

Trist, E. L. \& Bamforth K. W. (1951). Some social and psychological consequences of the longwall method of coal-getting: An examination of the psychological situation and defences of a work group in relation to the social structure and technological content of the work system. Human Relations, 4(3). doi:10.1177/001872675100400101

U.S. Bureau of Labor Statistics. (n.d.). Retrieved from https://www.bls.gov Wageman, R., Nunes, D. A., Buruss, J. A., \& Hackman, J. R. (2008). Senior leadership teams: What it takes to make them great. Boston, MA: Harvard Business Review Press. 
Wesley, D. (2019, January 14). The state of the 40 hour workweek [Blog post]. Retrieved from https://www.creditloan.com/blog/the-state-of-the-40hour-workweek/

\section{Author Contact}

Gabe Abella

gabe@kanbaniq.com

https:/www.linkedin.com/in/gabeabella/

Shannon Arvizu, Ph.D.

shannon@epicteams.co

https://epicteams.co

https://www.linkedin.com/in/shannonarvizu 